\title{
Níveis de uréia na ração de novilhos de quatro grupos genéticos: estimativa da produção de proteína microbiana por meio dos derivados de purinas na urina utilizando duas metodologias de coleta ${ }^{1}$
}

\author{
Luciana Navajas Rennó ${ }^{2 *}$, Sebastião de Campos Valadares Filho ${ }^{3}$, Rilene Ferreira Diniz \\ Valadares ${ }^{4}$, Mário Fonseca Paulino ${ }^{3}$, Francisco Palma Rennó ${ }^{2}$, Polyana Albino Silva ${ }^{2}$
}

${ }_{1}$ Pesquisa parcialmente financiada pela FAPEMIG/CNPq.

2 Programa de Pós-Graduação em Zootecnia, DZO/UFV, Viçosa-MG, CEP: 36571-000.

${ }^{3}$ Departamento de Zootecnia - UFV, Viçosa-MG. CEP: 36571-000. Bolsista do CNPq.

${ }^{4}$ Departamento de Veterinária - UFV, Viçosa-MG. CEP: 36571-000. Bolsista do CNPq.

RESUMO - Objetivou-se avaliar o efeito de quatro níveis de uréia na ração: 0; 0,65; 1,3 e 1,95\% na matéria seca (MS), sobre a estimativa da produção de proteína microbiana por meio dos derivados de purinas na urina, em duas metodologias de coleta em novilhos de quatro grupos genéticos: Holandês, 1/2 sangue Holandês-Guzerá, 1/2 sangue Holandês-Gir e Zebu. Os animais foram alimentados com $50 \%$ de feno de capim tifton-85 e 50\% de concentrado e distribuídos em quatro quadrados latinos (grupos genéticos) $4 \times 4$, sendo quatro animais, quatro períodos experimentais e quatro tratamentos (rações). As dietas continham aproximadamente $12 \%$ PB. As amostras de urina, em cada período experimental, foram obtidas a partir de coletas em 24 horas e por meio da coleta spot de urina, quando os animais urinaram espontaneamente. Na urina foram realizadas as análises dos derivados de purinas, alantoína e ácido úrico. Foram feitas comparações entre a produção microbiana usando as bases purinas no abomaso com os derivados de purinas na urina; entre as determinações da produção microbiana pelos derivados de purinas com duas equações distintas ou com as bases purinas no abomaso; e entre a estimativa da produção urinária, dos derivados de purinas e da produção microbiana através da coleta spot de urina com a coleta total de urina em 24 horas. A produção e as eficiências microbianas mostraram-se superiores para os animais holandeses, intermediárias para os mestiços e inferiores para os zebuínos. A estimativa da produção de compostos nitrogenados microbianos pode ser feita a partir da excreção dos derivados de purinas na urina. A coleta spot de urina consiste em metodologia rápida e eficaz na estimativa da excreção urinária dos derivados de purinas e da produção de compostos nitrogenados microbianos.

Palavras-chave: nitrogênio microbiano, novilhos, purinas na urina, uréia

\section{Urea levels in diet for steers of four genetic groups: microbial protein production by the urinary purine derivatives, using two collection methodologies}

\begin{abstract}
The effect of four dietary urea levels: 0, 0.65, 1.3 and 1.95\% in dry matter (DM), on the microbial protein production by means of the urinary purine derivatives was evaluated by using two collection methodologies in steers of four genetic groups: Holstein in, 1/2 Holstein-Guzera, $1 / 2$ Holstein-Gir and Zebu. Animals were fed diets with 50:50 tifton-85 bermudagrass hay to concentrate ratio and assigned to four $4 \times 4$ latin squares (genetic groups): four animals, four experimental periods and four treatments (diets) and were. Diets approximately contained 12\% CP. The urine samples, from each experimental period, were obtained from 24-h collection and spot urine collection, when the animals spontaneously urinated. Analyses of purine derivatives, allantoin and uric acid were performed in the urine. A comparison among the microbial production using the purine bases in the abomasum and urinary purine derivatives; determination of microbial production by purine derivatives using two different equations or purine bases method in the abomasum; and estimate of urinary of purine derivatives and microbial production by means of spot urine collection and by 24-h total urine collection, were performed. Production and microbial efficiency showed higher values for Holstein animals, intermediary values for crossbred and smaller values for Zebu. The estimation of microbial nitrogen compounds production could be performed from the excretion of urinary purine derivatives. The spot urine collection is a fast and efficient methodology to estimate the excretion of urinary purine derivatives and the microbial nitrogen compounds production.
\end{abstract}

Key Words: microbial nitrogen, steers, purine in the urine, urea

Este artigo foi recebido em 25/5/2005 e aprovado em 17/9/2007.

Correspondências devem ser enviadas para Inrenno@hotmail.com.

* Endereço atual: UNIPAC - Universidade Presidente Antonio Carlos, Juiz de Fora-MG. CEP: 36048-000. 


\section{Introdução}

O fato de a maior parte do nitrogênio que chega ao intestino delgado ser de origem microbiana atesta que a eficiência de crescimento microbiano tem considerável impacto na nutrição de ruminantes (Russell et al., 1992; Firkins et al., 1998). Ainda considerando que a proteína microbiana é de alta qualidade, torna-se importante maximizar sua síntese ruminal (Blümmel \& Lebzien, 2001).

Clark et al. (1992) destacaram que a composição das bactérias isoladas do rúmen apresenta variações descritas na literatura, com valores médios de 77,5\% para matéria orgânica (MO), 7,7\% para nitrogênio (N) total, 7,3\% para RNA-purinas e $13,7 \%$ para a relação N-RNA:N-total. Considerando dados de dez experimentos conduzidos no Brasil, Valadares Filho (1995) relatou valores médios de 89,2\% para o teor de matéria seca (MS) e 84,6; 7,1; 8,6; 4,6 e 17,6\% para os respectivos teores de MO, N total, RNA-purinas, lipídeos e relação N-RNA:N-total, expressos na base da MS.

A eficiência de síntese microbiana é expressa de diferentes formas: em função dos nutrientes digestíveis totais - NDT (NRC, 1989 e 2001), da MO degradada no rúmen - MODR (ARC, 1980), da energia metabolizável fermentável da dieta (AFRC, 1993) e dos carboidratos totais degradados no rúmen - CHODR, segundo o Cornell Net Carbohydrate and Protein System - CNCPS, descrito por Russell et al. (1992).

Os métodos utilizados para medir a quantidade de compostos nitrogenados microbianos baseiam-se em marcadores microbianos, como bases purinas (RNA), ácido 2,6 diaminopimélico (DAPA), ${ }^{35} \mathrm{~S}$ e ${ }^{15} \mathrm{~N}$, sendo que a utilização dessas metodologias requer animais preparados cirurgicamente. Nesse sentido, segundo Susmel et al. (1994), tem havido interesse crescente no desenvolvimento de técnicas não-invasivas que estimem a produção microbiana.

As pesquisas, ao longo dos últimos anos, confirmaram a relação entre produção de proteína microbiana e excreção urinária de derivados de purinas. Esta técnica admite que os ácidos nucléicos no duodeno são de origem predominantemente microbiana e, após digestão intestinal e absorção, os derivados de purinas são proporcionalmente recuperados na urina, principalmente na forma de alantoína, mas também como ácido úrico, hipoxantina e xantina (Perez et al., 1996). Rennó et al. (2000), trabalhando com novilhos, verificaram que a excreção de xantina e hipoxantina, por ser irrisória em bovinos, não precisa ser determinada.

A excreção de derivados de purinas está diretamente relacionada com a absorção de purinas e o conhecimento da relação N-purinas:N-total da massa microbiana (Chen \& Gomes, 1992) e pode ser utilizada desde que a excreção endógena de derivados de purinas e a relação quantitativa entre a excreção de derivados de purinas e a absorção de purinas tenham sido previamente determinadas (Verbic et al., 1990; Orellana Boero et al., 2001).

Métodos com base na excreção de derivados de purinas na urina são menos invasivos que a fistulação de animais, mas exigem coleta total de urina. Entretanto, pode ser possível simplificar a coleta de urina sob condições a campo (Chen \& Gomes, 1992). Em razão de a excreção de creatinina na urina ser relativamente constante em função do peso vivo (Valadares et al., 1997b) e usada como indicador da produção urinária, há possibilidade da estimativa da excreção dos derivados de purinas sem a coleta total de urina, pela utilização de uma única amostra de urina, denominada amostra spot (Valadares et al., 1999).

Leão et al. (2004) concluíram que a estimativa da produção de compostos nitrogenados microbianos utilizando a excreção urinária de derivados de purinas por meio da amostra spot de urina foi adequada, reforçando a viabilidade do uso desta metodologia.

Este trabalho foi conduzido com o objetivo de avaliar o efeito de quatro níveis de uréia na ração ( $0 ; 0,65 ; 1,3$ e 1,95\% na MS) sobre a estimativa da produção de proteína microbiana, por meio dos derivados de purinas na urina utilizando duas metodologias de coleta em novilhos de quatro grupos genéticos: Holandês, $1 / 2$ sangue HolandêsGuzerá, $1 \frac{1}{2}$ sangue Holandês-Gir e Zebu.

\section{Material e Métodos}

O local do experimento, as instalações, os animais, o sistema de alimentação, a composição das rações, a duração do período de adaptação e a determinação do fluxo de MS foram descritos em Rennó et al. (2005). Os 16 animais dos quatro grupos genéticos: Holandês, $1 / 2$ sangue HolandêsGuzerá (1/2 Hol-Guz), 1/2 sangue Holandês-Gir (1/2 Hol-Gir) e Zebu (com grau de sangue predominante da raça Indubrasil) foram distribuídos em quatro quadrados latinos (grupos genéticos) $4 \times 4$, sendo quatro animais com respectivos pesos médios iniciais de cada grupo de 330 , 294, 289 e $198 \mathrm{~kg}$, quatro períodos experimentais e quatro tratamentos (rações).

As rações foram formuladas à base de feno de capimtifton 85 (Cynodon spp) e concentrado, na relação 50:50, contendo em torno de $12 \%$ de PB, com níveis crescentes de uréia: 0; 0,65; 1,3 e 1,95\% na MS, sendo 12,70; 24,96; 37,51 e 45,95\% da PB na forma de compostos nitrogenados nãoprotéicos (Tabela 1).

No penúltimo dia do período de adaptação às dietas, foi efetuada a coleta spot de urina. Durante os seis dias subseqüentes, foram realizadas as coletas de fezes e 
digesta de abomaso para estimativa da digestibilidade, sendo que, no $3^{\underline{0}}$ dia deste período de coleta, foi realizada a coleta de urina em 24 horas. No último dia do período experimental, foi feita a coleta de conteúdo ruminal para isolamento de bactérias.

As amostras de urina, em cada período experimental, foram obtidas a partir de coletas em 24 horas (Valadares et al., 1997a), utilizando-se funis coletores adaptados aos animais. Mangueiras de borracha, acopladas aos funis, conduziram a urina até recipientes plásticos contendo $250 \mathrm{~mL}$ de solução de ácido sulfúrico $\left(\mathrm{H}_{2} \mathrm{SO}_{4}\right)$ a $20 \%$. Após a coleta, foi determinado o volume total de urina produzido, as amostras foram homogeneizadas e, em seguida, retiradas alíquotas de $100 \mathrm{~mL}$. Estas amostras de urina tiveram o $\mathrm{pH}$ ajustado abaixo de 3 e foram diluídas 3 a 4 vezes para evitar destruição bacteriana dos derivados de purinas urinários e precipitação de ácido úrico. Devidamente identificadas, foram armazenadas a $-15^{\circ} \mathrm{C}$ para posteriores análises laboratoriais.

As amostras spot de urina foram coletadas aproximadamente 4 horas após a alimentação, por micção espontânea. Nessa coleta utilizaram-se os mesmos funis descritos para a coleta de urina em 24 horas, sendo os mesmos retirados assim que o animal tivesse urinado. Também foram retiradas alíquotas de $100 \mathrm{~mL}$ de urina, adotando-se o mesmo procedimento para as amostras de urina coletadas em 24 horas.

No último dia de cada período experimental, foram coletadas amostras de digesta ruminal de cada animal para o isolamento de bactérias, conforme metodologia descrita por Cecava et al. (1990). As análises bromatológicas das bactérias foram realizadas segundo Silva \& Queiroz (2002). $\mathrm{O}$ indicador microbiano usado para a quantificação dos microrganismos foi as bases purinas, cuja determinação seguiu a técnica descrita por Ushida et al. (1985).

Na urina foram realizadas as análises de derivados de purinas (alantoína e ácido úrico), que foram feitas pelo método colorimétrico, conforme técnica de Fujihara et al. (1987), descrita por Chen \& Gomes (1992).

As purinas microbianas absorvidas ( $\mathrm{X}, \mathrm{mmol} / \mathrm{dia}$ ) foram calculadas a partir da excreção de derivados de purinas na urina (mmol/dia), por intermédio da equação: $\mathrm{Y}=0,85 \mathrm{X}+0,385 \mathrm{PV}^{0,75}$, em que 0,85 é a recuperação das purinas absorvidas como derivados urinários de purinas e 0,385 PV ${ }^{0,75}$, a contribuição endógena para a excreção de purinas (Verbic et al., 1990). Esse cálculo também foi efetuado segundo equação de Orellana Boero et al. (2001), que estimaram recuperação das purinas na urina de 0,84 e excreção endógena de $0,235 \mathrm{PV}^{0,75}$.
Tabela 1 - Teores dos nutrientes das rações contendo diferentes níveis de uréia

\begin{tabular}{lcccc}
\hline \multirow{2}{*}{ Item } & \multicolumn{4}{c}{ Nível de uréia (\%) } \\
\cline { 2 - 5 } & 0 & 0,65 & 1,5 & 1,95 \\
\hline MS (\%) & 86,29 & 85,97 & 85,96 & 86,08 \\
MO $^{1}$ & 95,20 & 95,28 & 95,65 & 95,73 \\
PB $^{1}$ & 12,05 & 12,14 & 12,45 & 12,36 \\
NNP $^{2}$ & 12,70 & 24,96 & 37,51 & 45,95 \\
NIDA $^{2}$ & 14,45 & 14,51 & 14,59 & 14,67 \\
NIDN $^{2}$ & 19,05 & 19,13 & 19,23 & 19,33 \\
EE $^{1}$ & 2,03 & 2,02 & 2,05 & 2,02 \\
CHO $^{1}$ & 81,13 & 81,12 & 81,15 & 81,35 \\
FDNcp $^{1,3}$ & 41,07 & 40,97 & 40,78 & 41,24 \\
CNFcP $^{1,3,4}$ & 40,06 & 41,334 & 42,734 & 43,654 \\
FDA $^{1}$ & 23,81 & 23,62 & 22,81 & 22,51 \\
LIG $^{1}$ & 3,54 & 3,49 & 3,68 & 3,63 \\
NDT $^{1}$ & 70,23 & 71,08 & 71,34 & 69,86 \\
\hline
\end{tabular}

$\mathrm{CHO}$ - carboidratos totais; $\mathrm{CNF}=$ carboidratos não-fibrosos.

$1 \%$ da MS; 2 \% do nitrogênio total; ${ }^{3}$ Com correção para cinzas e proteína

${ }^{4}$ CNF para dietas com uréia $=100-[(P B-P B$ da uréia + \%uréia $)+E E+$ Cinzas + FDNcp)] (Hall, 2001).

O fluxo intestinal de compostos nitrogenados (N) microbianos (g N/dia) foi calculado em função das purinas microbianas absorvidas (X, mmol/dia), utilizando-se a equação $=(70 \mathrm{X}) /(0,83 \mathrm{x}$ relação $\mathrm{N}$-purina: $\mathrm{N}$-total nas bactérias $\mathrm{x} 1000$ ), em que 70 representa o conteúdo de $\mathrm{N}$ nas purinas (mg N/mmol) e 0,83, a digestibilidade das purinas microbianas (Chen \& Gomes, 1992). Foi utilizada para este cálculo a relação N-purina:N-total média para cada tratamento, em \% da MO, obtida das bactérias ruminais.

Os dados foram avaliados por meio de análises de variância e regressão, utilizando-se o Sistema de Análises Estatísticas e Genéticas - SAEG (UFV, 1995). Adotou-se delineamento em quadrado latino $4 \times 4$, sendo cada grupo genético considerado um quadrado latino. Os quatro quadrados latinos foram analisados em conjunto. Para comparação entre os grupos genéticos, foi realizado o teste Tukey, a 5\% de probabilidade Os critérios utilizados para escolha do modelo foram o fenômeno estudado, o coeficiente de determinação ( $\mathrm{r}^{2}$, em \%), que foi calculado como a relação entre a soma de quadrado da regressão e a soma de quadrado de tratamento, e a significância dos coeficientes de regressão utilizando-se o teste t, a 5\% de probabilidade.

A comparação entre a produção microbiana utilizando as bases purinas no abomaso com os derivados de purinas na urina e, também, entre as determinações da produção microbiana entre a equação de Orellana Boero et al. (2001) e a de Verbic et al. (1990) ou com as bases purinas no abomaso, além da comparação entre a estimativa da produção urinária, dos derivados de purinas e da produção microbiana através da coleta spot de urina com a coleta total de urina em 24 horas, foram realizadas pelo teste $\mathrm{t}$, a $5 \%$ de probabilidade. 


\section{Resultados e Discussão}

Os teores de MS, carboidratos totais (CHO), extrato etéreo (EE), nitrogênio total (NT) e N do ácido ribonucléico (N-RNA) das bactérias não diferiram entre os grupos genéticos ( $\mathrm{P}>0,05)$ (Tabela 2). As quantidades de $\mathrm{MO}$ e a relação N-RNA:NT diferiram entre os grupos genéticos $(\mathrm{P}<0,05)$. Os valores médios de 80,74 e 74,61\%, para os respectivos teores médios de MS e MO das bactérias ruminais, estão próximos dos encontrados por Valadares Filho et al.(1990b), em estudo com animais holandeses, nelores, búfalos e 7/8 Holandês-Zebu, no qual relataram valores de 82,35 e 71,43\% para os teores de MS e MO das bactérias ruminais, respectivamente.

Observa-se que todas as variáveis avaliadas na Tabela 3 não foram influenciadas pela inclusão de quantidades crescentes de uréia na dieta.

O teor médio de MS das bactérias foi de 80,74\%, inferior ao de $85,00 \%$ relatado por Cabral (2002), em estudo com três volumosos, e de 89,20\% relatado por Valadares Filho (1995), em revisão de dados da literatura nacional. O valor de 74,61\% para a MO foi próximo ao citado por Clark et al. (1992), de 77,5\%, e inferior às médias de 79,33 e 91,07\% relatadas por Ítavo et al. (2002) e Cardoso et al. (2000), respectivamente. Este baixo valor encontrado para o teor de MO nas bactérias decorreu, possivelmente, do alto teor de cinzas nas bactérias, em razão do uso de solução salina durante o processo de isolamento. Este fato foi relatado por Leão (2002) e Cabral (2002), que utilizaram a mesma metodologia descrita neste estudo, encontrando porcentagem de MO nas bactérias de 71,5 e 72,90, respectivamente.

O teor de EE médio das bactérias ruminais de 10,50\% foi semelhante ao relatado por Dias et al. (2000) e Tibo et al. (2000), de 10,53 e 10,51\%, respectivamente, e superior aos 3,39\% relatados por Cabral (2002), 4,47\% obtidos por Ítavo et al. (2002) e ao valor médio de 4,25\% descrito por Van Soest (1994). Os valores de NT, expressos tanto na MS como na MO, estão muito próximos dos 6,86 e 9,70\% relatados por Leão (2002), respectivamente.

A relação N-RNA:NT das bactérias ruminais, expressa na base da MS, apresentou média de 19,50, valor superior aos citados por Clark et al. (1992) e Valadares Filho (1995), de 13,7 e 17,6\%, respectivamente, porém inferior à media de 24,0, encontrada por Leão (2002). Quando esta relação foi expressa em \% da MO, a média foi de $14,51 \%$, valor muito próximo ao relatado por Ítavo et al. (2002), de 14,78\%, e inferior ao apresentado por Cabral (2002), de 18,40\%. Vale salientar que a quantificação da produção microbiana no
Tabela 2 - Composição do $\mathrm{N}$ do ácido ribonucléico (N-RNA) e relação N-RNA:NT das bactérias isoladas do rúmen, em função dos grupos genéticos

\begin{tabular}{lrrrrr}
\hline \multirow{2}{*}{ Item } & \multicolumn{4}{c}{ Grupo genético } & \multicolumn{1}{c}{ CV\% } \\
\cline { 2 - 5 } & Holandês & 1/2Hol-Guz & 1/2Hol-Gir & Zebu & \\
\hline MS (\%) & 82,39a & 80,27a & 80,03a & $80,26 a$ & 4,70 \\
MO $^{1}$ & $77,11 \mathrm{a}$ & $73,07 \mathrm{~b}$ & $72,45 \mathrm{~b}$ & $75,77 \mathrm{ab}$ & 4,44 \\
$\mathrm{CHO}^{1}$ & $22,12 \mathrm{a}$ & $19,89 \mathrm{a}$ & $20,41 \mathrm{a}$ & $22,05 \mathrm{a}$ & 17,74 \\
$\mathrm{EE}^{1}$ & $10,85 \mathrm{a}$ & $10,48 \mathrm{a}$ & $10,06 \mathrm{a}$ & $10,64 \mathrm{a}$ & 9,65 \\
$\mathrm{NT}^{1}$ & $7,06 \mathrm{a}$ & $6,83 \mathrm{a}$ & $6,72 \mathrm{a}$ & $6,89 \mathrm{a}$ & 7,67 \\
$\mathrm{NT}^{2}$ & $9,16 \mathrm{a}$ & $9,39 \mathrm{a}$ & $9,28 \mathrm{a}$ & $9,12 \mathrm{a}$ & 7,54 \\
N-RNA $^{1}$ & $1,40 \mathrm{a}$ & $1,44 \mathrm{a}$ & $1,32 \mathrm{a}$ & $1,20 \mathrm{a}$ & 16,90 \\
N-RNA:NT & $19,80 \mathrm{ab}$ & $21,07 \mathrm{a}$ & $19,75 \mathrm{ab}$ & $17,37 \mathrm{~b}$ & 13,82
\end{tabular}

Médias seguidas de mesma letra, na linha, não diferem $(P<0,05)$ pelo teste Tukey.

${ }^{1}$ Expresso em \% da MS.

Tabela 3 - Composição do $\mathrm{N}$ do ácido ribonucléico (N-RNA) e relação N-RNA:NT das bactérias isoladas do rúmen, em função dos níveis de uréia (NU) da ração

\begin{tabular}{|c|c|c|c|c|c|}
\hline \multirow[t]{2}{*}{ Variável } & \multicolumn{4}{|c|}{ Nível de uréia } & \multirow[t]{2}{*}{ Regressão } \\
\hline & 0 & 0,65 & 1,3 & 1,95 & \\
\hline MS (\%) & 80,18 & 80,45 & 81,96 & 80,36 & $\hat{\mathrm{Y}}=80,74$ \\
\hline $\mathrm{MO}^{1}$ & 73,59 & 75,40 & 75,46 & 73,97 & $\hat{\mathrm{Y}}=74,61$ \\
\hline $\mathrm{CHO}^{1}$ & 19,85 & 20,78 & 22,80 & 21,03 & $\hat{\mathrm{Y}}=21,12$ \\
\hline $\mathrm{EE}^{1}$ & 10,81 & 10,24 & 10,33 & 10,64 & $\hat{\mathrm{Y}}=10,50$ \\
\hline $\mathrm{NT}^{1}$ & 6,87 & 7,10 & 6,77 & 6,77 & $\hat{\mathrm{Y}}=6,88$ \\
\hline $\mathrm{NT}^{2}$ & 9,37 & 9,44 & 8,99 & 9,16 & $\hat{\mathrm{Y}}=9,24$ \\
\hline N-RNA ${ }^{1}$ & 1,33 & 1,39 & 1,29 & 1,36 & $\hat{\mathrm{Y}}=1,34$ \\
\hline N-RNA:NT ${ }^{1}$ & 19,24 & 19,61 & 19,15 & 19,99 & $\hat{\mathrm{Y}}=19,50$ \\
\hline
\end{tabular}

${ }^{1}$ Expresso em \% da MS.

abomaso pelas bases purinas é determinada utilizando essa relação nas bactérias isoladas de rúmen.

Nota-se que, para a MODR e os CHODR, os animais holandeses e os mestiços não diferiram entre si $(\mathrm{P}>0,05)$, e foram superiores aos zebuínos $(\mathrm{P}<0,05)$ (Tabela 4). Estes resultados podem ser justificados pelos maiores valores observados para o consumo de MS, MO e CHO apresentado pelos holandeses, intermediários para os mestiços e menores para os zebuínos (Rennó et al.,2005). Maiores consumos de MS foram observados por Leão (2002) com o incremento de oferta de alimentos, possibilitando, assim, quantidades crescentes de MODR e CHODR.

Para o N microbiano e a produção de MSmic, os animais holandeses foram superiores aos demais $(\mathrm{P}<0,05)$. Para os mestiços, essas variáveis não diferiram entre si $(\mathrm{P}>0,05)$, sendo superiores $(\mathrm{P}<0,05)$ aos zebuínos. Esse comportamento pode ser explicado pelos resultados apresentados para as ingestões de MS pelos grupos genéticos. Segundo Owens et al. (1986), a produção de N microbiano, geral- 
mente, aumenta com a elevação do consumo de MS, pois, provavelmente, há incremento da taxa de passagem de líquidos e sólidos em animais submetidos a ingestões mais altas, o que diminui a proporção de energia utilizada pelas bactérias para mantença. Vale salientar que a produção de $\mathrm{N}$ microbiano, determinada utilizando as bases purinas como indicador, foi calculada utilizando-se a relação N-RNA:NT das bactérias ruminais expressa na MO.

A eficiência microbiana, expressa em g Nmic/kg MODR, foi superior para os novilhos holandeses $(\mathrm{P}<0,05)$ em relação aos mestiços e zebuínos, que não diferiram entre si. Discordando deste resultado, Valadares Filho et al. (1990a) não encontraram diferenças na eficiência microbiana entre novilhos holandeses e nelores, relatando média de 26,15 g Nmic/kg MODR. O ARC (1980) relatou para bovinos valor médio de 32 g Nmic/kg MODR, para rações sem uréia. Ao se compararem esses valores com os encontrados nesta pesquisa, observa-se que estes estão supostamente baixos, talvez em decorrência da alta relação N-RNA:NT das bactérias ruminais.

Quando expressa em g Nmic/kg CHODR e g PBmic/100 g NDT, a eficiência de síntese microbiana apresentada pelo holandeses não diferiu do $1 \frac{1}{2}$ Holandês-Guzerá $(\mathrm{P}>0,05)$, mas foi superior aos grupos $1 \frac{1}{2}$ Holandês-Gir e Zebu $(\mathrm{P}<0,05)$. Por outro lado, o grupo genético $1 / 2$ Holandês-Guzerá não diferiu dos 1/2 Holandês-Gir e Zebu. Os resultados da eficiência microbiana, expressa em g PBmic/100 g NDT, corroboram as considerações do NRC (1996) de que, com a redução do consumo de NDT, pode ocorrer redução na eficiência de síntese microbiana, em conseqüência de menores taxas de passagem.

A MSmic, quando expressa em função dos CHODR, não diferiu entre os animais holandeses e mestiços $(\mathrm{P}>0,05)$, contudo, estes últimos não diferiram dos Zebu $(\mathrm{P}>0,05)$. De forma geral, as eficiências microbianas apresentaram-se superiores para os animais holandeses, intermediárias para os animais mestiços e inferiores para os zebuínos, refletindo o comportamento do consumo de MS dos respectivos grupos genéticos (Rennó et al., 2005).

A degradação ruminal da $\mathrm{MO}$ e dos $\mathrm{CHO}$ não foi influenciada pela inclusão de uréia na ração $(\mathrm{P}>0,05)$ (Tabela 5), possivelmente em razão de as ingestões de MS, MO e CHO não terem sido afetadas pelos tratamentos (Rennó et al., 2005).

$\mathrm{O}$ fluxo de $\mathrm{N}$ microbiano apresentou comportamento linear decrescente $(\mathrm{P}<0,05)$ e a MSmic não foi influenciada pela adição de uréia na dieta. Segundo o NRC (2001), há evidências de que aminoácidos e especialmente peptídeos estimulam a produção de microrganismos que crescem em fontes energéticas rapidamente degradáveis. Entretanto,
Tabela 4 - Matéria orgânica degradada no rúmen (MODR) carboidratos totais degradados no rúmen (CHODR) compostos nitrogenados microbianos (Nmic) e matéria seca microbiana (MSmic) presentes no abomaso, e eficiência microbiana expressa em $\mathrm{g} \mathrm{Nmic/kg} \mathrm{MODR}$ (1), g Nmic/kg CHODR (2), g MSmic/kg CHODR (3) e g PBmic/100 g NDT (4), em função dos grupos genéticos

\begin{tabular}{lrrrrr}
\hline \multirow{2}{*}{ Item } & \multicolumn{4}{c}{ Grupo genético } & \multirow{2}{*}{ CV\% } \\
\cline { 2 - 5 } & Holandês & $1 / 2$ Hol-Guz & $1 / 2$ Hol-Gir & Zebu \\
\hline MODR $^{1}$ & $4,44 \mathrm{a}$ & $4,17 \mathrm{a}$ & $4,05 \mathrm{a}$ & $1,92 \mathrm{~b}$ & 14,25 \\
CHODR $^{1}$ & $4,20 \mathrm{a}$ & $3,80 \mathrm{a}$ & $3,63 \mathrm{a}$ & $1,80 \mathrm{~b}$ & 13,86 \\
Nmic $^{2}$ & $91,74 \mathrm{a}$ & $70,86 \mathrm{~b}$ & $60,74 \mathrm{~b}$ & $31,43 \mathrm{c}$ & 19,21 \\
MSmic $^{2}$ & $1.329,89 \mathrm{a}$ & $1.039,22 \mathrm{~b}$ & $907,96 \mathrm{~b}$ & $457,83 \mathrm{c}$ & 23,37 \\
1 & $20,70 \mathrm{a}$ & $17,13 \mathrm{~b}$ & $15,46 \mathrm{~b}$ & $16,33 \mathrm{~b}$ & 16,14 \\
2 & $21,66 \mathrm{a}$ & $18,77 \mathrm{ab}$ & $17,14 \mathrm{~b}$ & $17,35 \mathrm{~b}$ & 14,78 \\
3 & $311,50 \mathrm{a}$ & $276,08 \mathrm{ab}$ & $258,70 \mathrm{~b}$ & $251,74 \mathrm{~b}$ & 17,06 \\
4 & $9,32 \mathrm{a}$ & $8,25 \mathrm{ab}$ & $7,71 \mathrm{~b}$ & $7,72 \mathrm{~b}$ & 15,58 \\
\hline
\end{tabular}

Médias seguidas de mesma letra, na linha, não diferem $(P<0,05)$ pelo teste Tukey.

${ }^{1} \mathrm{~kg} / \mathrm{dia} ;{ }^{2} \mathrm{~g} / \mathrm{dia}$.

quando os substratos energéticos são fermentados lentamente, esta estimulação não ocorre. Resultados distintos aos deste estudo foram apresentados por Kropp et al. (1977), em avaliação da substituição da PB do farelo de soja por uréia nos níveis de $0,25,50$ ou 75\%, para novilhos alimentados com $75 \%$ de feno de baixa qualidade. Os autores relataram que a produção de $\mathrm{N}$ microbiano foi relativamente constante, independentemente do nível de adição de uréia.

A eficiência microbiana, expressa em g Nmic em função da MODR e CHODR, mostrou comportamento linear decrescente com a inclusão de uréia na ração, provavelmente em decorrência do comportamento observado para o fluxo de $\mathrm{N}$ microbiano.

A eficiência microbiana, quando expressa em g MSmic/ kg CHODR, não foi influenciada pela adição de uréia à dieta e apresentou média de 274,51 g MSmic/kg CHODR, apesar de ter mostrado redução numérica para o nível de 1,95\% de uréia. Esta média foi inferior à relatada por Ítavo et al. (2002), de 392,40 g MSmic/kg CHODR, e à considerada pelo CNCPS, de $400 \mathrm{~g}$ MSmic/kg CHODR (Russell et al., 1992).

A eficiência de síntese microbiana expressa em g PBmic/ $100 \mathrm{~g}$ NDT apresentou comportamento linear decrescente, em função dos níveis de uréia da ração. Os valores encontrados foram inferiores aos descritos por Leão et al. (2004), de 11,10 g PBmic/100 g NDT, e aos citados pelo NRC (1996, 2001), que admitiu o valor médio de 13 g PBmic/100 g NDT.

Possivelmente, o valor menor para a eficiência microbiana, independentemente de como foi expressa, em relação aos dados da literatura, ocorre em decorrência da alta relação N-RNA:NT das bactérias ruminais, obtida pelas bases purinas no abomaso. 
Nota-se que, para todas as comparações efetuadas a partir dos dados apresentados na Tabela 6, a produção dos compostos nitrogenados microbianos não diferiu entre as metodologias (equações de Verbic et al., 1990 e de Orellana Boero et al., 2001) e equações utilizadas ( $P>0,05)$.

Perez et al. (1996), em estudo com ovinos, e Martín-Orúe et al. (2000), em trabalho com novilhas, relataram que o fluxo de compostos nitrogenados microbianos, determinado a partir das bases purinas no duodeno ou pela excreção dos derivados de purinas na urina, não diferiu. Rennó et al. (2000), em estudo com novilhos mestiços e zebuínos, comparando o método das bases purinas no abomaso com o dos derivados de purinas na urina, verificaram que, em ambos os grupos genéticos, a produção microbiana pode ser estimada pela excreção dos derivados de purinas na urina.

As médias para a produção de compostos nitrogenados microbianos, determinados com as bases purinas no abomaso, e os derivados de purinas na urina, calculados pela equação de Verbic et al. (1990) para os grupos genéticos Holandês foram de 91,74 e 90,16 e para os animais 1/2 Holandês-Guzerá, de 70,86 e 72,92. Para os 1⁄2 Holandês-Gir foram de 60,74 e 66,37 e para os novilhos Zebu, foram de 31,43 e 31,29 g Nmic/dia, respectivamente, para cada metodologia supracitada. Em todas as comparações, para cada grupo genético, a produção de $\mathrm{N}$ microbiano não diferiu entre as metodologias utilizadas $(\mathrm{P}>0,05)$.

Orellana Boero et al. (2001) estimaram a excreção endógena de purinas em $0,235 \mathrm{PV}^{0,75}$ e a recuperação das purinas na urina em 0,84 . Estes valores foram inferiores aos descritos por Verbic et al. (1990), de $0,385 \mathrm{PV}^{0,75}$ para a excreção endógena e 0,85 para a recuperação urinária das purinas. A última equação supracitada, por ter sido feita anteriormente, é amplamente usada na literatura (De Boever et al., 1998; Rennó et al., 2000; Yu et al., 2002; Leão et al., 2004), contudo, deve ser considerada a outra equação, que necessita de validação. A equação de Orellana Boero et al. (2001) apresenta-se relevante, pois os demais trabalhos da literatura relataram valores superiores aos de Verbic et al. (1990) para a excreção endógena das purinas, podendo, muitas vezes subestimar a produção microbiana.

A média geral para os compostos nitrogenados microbianos determinados pelas bases purinas no abomaso foi de 63,69 g N/dia e pelos derivados de purinas na urina, calculados utilizando-se a equação de Verbic et al. (1990), de 65,19 . Os valores estimados a partir da equação de Orellana Boero et al. (2001) foram de 73,48 g N/dia.

Martín-Orúe et al. (2000), em estudo com novilhas submetidas a quatro níveis de proteína degradável no rúmen, relataram que a produção microbiana estimada a partir da excreção urinária dos derivados de purinas, usando a equação de Verbic et al. (1990), foi 12\% inferior à determinada pela equação de Orellana Boero et al. (2001), contudo, não apresentou diferença estatística.

Houve diferença $(\mathrm{P}<0,05)$ somente para os volumes urinários obtidos a partir da coleta de urina em 24 horas e estimados pela coleta spot de urina $(\mathrm{P}<0,01)$. Contudo, essa diferença de volume entre essas coletas, que foram realizadas em dias diferentes, não interfere nas estimativas das excreções. Apesar desta diferença, a coleta spot de urina estimou satisfatoriamente as excreções urinárias dos derivados de purinas e, subseqüentemente, a produção dos compostos nitrogenados microbianos. Silva et al. (2001), trabalhando com vacas leiteiras, com a inclusão de níveis crescentes de uréia na ração ( 0 a 2,1\% na MS), não encontraram diferença para médias obtidas e estimadas, para os mesmos parâmetros observados neste estudo.

Tabela 5 - Matéria orgânica degradada no rúmen (MODR), carboidratos totais degradados no rúmen (CHODR), compostos nitrogenados microbianos (Nmic) e matéria seca microbiana (MSmic) presentes no abomaso e eficiência microbiana expressa em $\mathrm{g}$ Nmic/ kg MODR (1), g Nmic/kg CHODR (2), g MSmic/kg CHODR (3) e g PBmic/100 g NDT (4), em função dos níveis de uréia (NU) da ração

\begin{tabular}{|c|c|c|c|c|c|c|}
\hline Item & \multicolumn{4}{|c|}{ Nível de uréia } & Regressão & $r^{2}$ \\
\hline MODR $^{5}$ & 3,86 & 3,57 & 3,58 & 3,56 & $\hat{\mathrm{Y}}=3,64$ & \\
\hline CHODR $^{5}$ & 3,59 & 3,30 & 3,28 & 3,26 & $\hat{\mathrm{Y}}=3,36$ & \\
\hline $\mathrm{Nmic}^{6}$ & 70,36 & 62,38 & 65,59 & 56,44 & $\hat{\mathrm{Y}}=69,476-5,932 * \mathrm{NU}$ & 0,73 \\
\hline MSmic $^{6}$ & $1.039,60$ & 885,85 & 975,87 & 833,59 & $\hat{\mathrm{Y}}=933,73$ & \\
\hline 2 & 19,31 & 19,22 & 19,88 & 16,51 & $\hat{\mathrm{Y}}=19,888-1,186^{*} \mathrm{NU}$ & 0,44 \\
\hline 3 & 282,51 & 272,68 & 296,14 & 246,70 & $\hat{\mathrm{Y}}=274,51$ & \\
\hline 4 & 8,65 & 8,50 & 8,50 & 7,36 & $\hat{\mathrm{Y}}=8,835-0,598 * \mathrm{NU}$ & 0,70 \\
\hline
\end{tabular}

* Significativo $(P<0,05)$ pelo teste $t$.

$5 \mathrm{~kg} / \mathrm{dia} ;{ }^{6} \mathrm{~g} / \mathrm{dia}$. 
Tabela 6 - Produção de compostos nitrogenados microbianos (Nmic, g/dia), determinadas com as bases purinas no abomaso (BPA) e os derivados de purinas na urina (DP), utilizando as equações 1 (Verbic et al., 1990) e 2 (Orellana Boero et al., 2001), para cada nível de uréia da ração

\begin{tabular}{|c|c|c|c|c|c|c|c|}
\hline \multirow[t]{3}{*}{ Nível } & \multirow{3}{*}{$\mathrm{N}$} & \multicolumn{3}{|c|}{ Método } & \multirow{3}{*}{ BPAx 1} & \multirow{3}{*}{ BPAx 2} & \multirow{3}{*}{$1 \times 2$} \\
\hline & & \multirow[t]{2}{*}{ BPA } & \multicolumn{2}{|c|}{ DP } & & & \\
\hline & & & 1 & 2 & & & \\
\hline 0 & 16 & 70,36 & 68,52 & 77,18 & ns & ns & ns \\
\hline 0,65 & 16 & 62,38 & 64,59 & 72,63 & ns & ns & ns \\
\hline 1,3 & 16 & 65,59 & 70,60 & 78,93 & ns & ns & ns \\
\hline 1,95 & 16 & 56,44 & 57,03 & 65,18 & ns & ns & ns \\
\hline
\end{tabular}

ns = não-significativo $(P>0,05)$ pelo teste $t$.

$\mathrm{n}=$ número de observações.

Chen et al. (1995) relataram que a amostra spot de urina pode não ter sensibilidade suficiente para a comparação entre diferentes tratamentos em ovinos. No entanto, Valadares et al. (1999) descreveram que a coleta spot é benéfica para a estimativa da excreção de derivados de purinas e outros metabólitos relativos às diferenças entre dietas de vacas.

O volume urinário diferiu entre os animais $(\mathrm{P}<0,05)$, sendo superior nos grupos $1 \frac{1}{2}$ Holandês-Guzerá e Zebu, mas não diferiu dos holandeses $(\mathrm{P}>0,05)$. Este último, contudo, não foi diferente dos animais $1 \frac{1}{2}$ Holandês-Gir. Para as excreções dos derivados de purinas, a de alantoína apresentou-se superior para os animais holandeses e $1 / 2$ Holandês-Guzerá. Contudo, estes últimos não diferiram dos $1 / 2$ Holandês-Gir $(\mathrm{P}>0,05)$, sendo as menores excreções obtidas para os zebuínos. As excreções de ácido úrico e purinas totais foram superiores para os animais holandeses, intermediárias para os mestiços e inferiores para os zebuínos (Tabela 8).

As purinas microbianas absorvidas não diferiram entre os animais do grupo genético Holandês e $1 / 2$ HolandêsGuzerá $(\mathrm{P}>0,05)$, contudo estes últimos não diferiram dos $1 / 2$ Holandês-Gir $(\mathrm{P}>0,05)$. Os novilhos Zebu mostraram o menor valor para esta variável. A produção de compostos nitrogenados microbianos indicou diferenças semelhantes verificadas entre os grupos genéticos para as purinas microbianas absorvidas. Esse fato é decorrente dos cálculos dos compostos nitrogenados microbianos realizados a partir das purinas microbianas absorvidas. As diferenças entre os grupos genéticos para a produção microbiana estimada pelos derivados de purinas urinários, de maneira geral, foram semelhantes à produção microbiana determinada pelas bases purinas no abomaso (Tabela 4).

O volume urinário não foi influenciado pelos níveis de uréia da ração $(P>0,05)$ (Tabela 9). Silva et al. (2001) não encontraram efeito da adição de uréia em níveis crescentes na dieta $(0 ; 0,7 ; 1,4$ e 2,1\% na MS) de vacas lactantes sobre
Tabela 7 - Volume urinário (VUR) em L/dia; excreções urinárias de alantoína (ALA), ácido úrico (AcU) e purinas totais (PUR) em mmol/dia; alantoína (ALA\%) e ácido úrico (AcU\%), em \% do total de purinas; purinas microbianas absorvidas (PUab) em mmol/dia e compostos nitrogenados microbianos (Nmic), em g/dia

\begin{tabular}{lrrl}
\hline \multirow{2}{*}{ Item } & \multicolumn{2}{c}{ Média } & \multirow{2}{*}{$\mathrm{P}$} \\
\cline { 2 - 3 } & Obtida & Estimada & \\
\hline VUR & 6,80 & 12,76 & $* *$ \\
ALA & 112,92 & 108,26 & $\mathrm{~ns}$ \\
AcU & 10,17 & 9,51 & $\mathrm{~ns}$ \\
PUR & 123,10 & 117,76 & $\mathrm{~ns}$ \\
ALA\% & 91,70 & 91,93 & $\mathrm{~ns}$ \\
AcU\% & 8,30 & 8,07 & $\mathrm{~ns}$ \\
PUab & 112,03 & 105,90 & $\mathrm{~ns}$ \\
Nmic $^{1}$ & 65,19 & 61,62 & $\mathrm{~ns}$ \\
\hline
\end{tabular}

ns e ${ }^{* *}$ Não-significativo e significativo a $1 \%$ de probabilidade, respectivamente, pelo teste t.

${ }^{1}$ Usando relação N RNA: N Total para cada tratamento em \% da MO e equação de Verbic et al. (1990)

Tabela 8 - Volume urinário (VUR) em L/dia; excreções urinárias de alantoína (ALA), ácido úrico (AcU) e purinas totais (PUR) em mmol/dia; purinas microbianas absorvidas (PUab) em mmol/dia, e compostos nitrogenados microbianos(Nmic) presentes no intestino, expressos em gramas por dia

\begin{tabular}{|c|c|c|c|c|c|}
\hline \multirow[t]{2}{*}{ Item } & \multicolumn{4}{|c|}{ Grupo genético } & \multirow[t]{2}{*}{$\mathrm{CV} \%$} \\
\hline & Holandês & $1 / 2 \mathrm{Hol}-\mathrm{Guz}$ & $1 / 2 \mathrm{Hol}-\mathrm{Gir}$ & Zebu & \\
\hline \multirow[t]{2}{*}{ VUR } & $6,03 a b$ & $7,99 a$ & $5,16 \mathrm{~b}$ & $8,02 \mathrm{a}$ & 31,68 \\
\hline & \multicolumn{4}{|c|}{ Derivados de purinas na urina } & \\
\hline ALA & $150,02 \mathrm{a}$ & $124,45 a b$ & $115,83 b$ & $61,40 c$ & 18,62 \\
\hline $\mathrm{AcU}$ & $13,74 \mathrm{a}$ & $11,62 b$ & $10,02 b$ & $5,31 \mathrm{c}$ & 27,14 \\
\hline \multirow[t]{2}{*}{ PUR } & $163,76 a$ & $136,08 b$ & $125,85 b$ & $66,71 \mathrm{c}$ & 18,54 \\
\hline & \multicolumn{4}{|c|}{ PUab } & \multirow{3}{*}{23,71} \\
\hline \multirow[t]{2}{*}{ PUab } & $154,92 \mathrm{a}$ & $125,37 a b$ & $114,17 b$ & $53,64 c$ & \\
\hline & \multicolumn{4}{|c|}{ Compostos nitrogenados microbianos } & \\
\hline $\mathrm{Nmic}^{1}$ & 90,16 a & 72,92ab & $66,37 b$ & $31,29 c$ & 23,98 \\
\hline
\end{tabular}

Médias seguidas de mesma letra, na linha, não diferem $(P<0,05)$ pelo teste Tukey.

1 Usando relação N RNA: N Total para cada tratamento em \% da $\mathrm{MO}$ e equação de Verbic et al. (1990). 
Tabela 9 - Volume urinário (VUR) em L/dia; excreções urinárias de alantoína (ALA), ácido úrico (AcU) e purinas totais (PUR) em mmol/ dia; purinas microbianas absorvidas (PUab), em mmol/dia; e compostos nitrogenados microbianos presentes no intestino delgado (Nmic), em g/dia, em função dos níveis de uréia (NU) da ração

\begin{tabular}{|c|c|c|c|c|c|c|}
\hline Item & \multicolumn{4}{|c|}{ Nível de uréia } & Regressão & $r^{2}$ \\
\hline \multirow[t]{2}{*}{ VUR } & 6,54 & 6,48 & 6,88 & 7,28 & \multirow[t]{2}{*}{$\hat{\mathrm{Y}}=6,80$} & \\
\hline & \multicolumn{4}{|c|}{ Derivados de purinas na urina } & & \\
\hline ALA & 114,36 & 113,63 & 120,21 & 103,49 & $\hat{\mathrm{Y}}=112,92$ & \\
\hline PUR & & Purinas $\mathrm{r}$ & absorvic & & $\hat{\mathrm{Y}}=123,10$ & \\
\hline \multirow[t]{2}{*}{ PUab } & 114,72 & 113,2 & 120,37 & 99,81 & \multirow[t]{2}{*}{$\hat{\mathrm{Y}}=112,03$} & \\
\hline & \multicolumn{4}{|c|}{ Compostos nitrogenados microbianos } & & \\
\hline
\end{tabular}

** Significativo a $1 \%$ de probabilidade pelo teste $t$.

1 Usando relação N RNA: N Total para cada tratamento em \% da MO e equação de Verbic et al. (1990).

os volumes urinários obtidos em coletas de urina em 24 horas e estimado pela coleta spot. Oliveira et al. (2001), em estudo com os mesmos níveis de uréia supracitados, relataram não ter havido efeito desses níveis sobre o volume urinário estimado. Contudo, o volume urinário obtido apresentou comportamento linear crescente em função dos níveis de uréia.

O ácido úrico apresentou comportamento linear decrescente em função da adição de uréia na dieta $(\mathrm{P}<0,05)$.

As excreções de alantoína e de purinas totais não foram afetadas pelos tratamentos $(\mathrm{P}>0,05)$, porém mostraram os menores valores numéricos para o maior nível de uréia. Este comportamento foi semelhante ao apresentado para as purinas microbianas absorvidas e os compostos nitrogenados microbianos, o que está de acordo com Vagnoni et al. (1997), os quais afirmaram que a metodologia de excreção dos derivados de purinas na urina pode estimar o fluxo de compostos nitrogenados microbianos e, ainda, a excreção de alantoína reflete a excreção das purinas totais, visto que é encontrada em maior proporção, em torno de $85 \%$ dos derivados de purinas (Verbic et al., 1990). Neste trabalho, a proporção de alantoína em relação às purinas totais foi de 91,70 e 91,93\%, respectivamente, para valores obtido e estimado (Tabela 6). Leão et al. (2004) relataram valor médio de 87,90\% de alantoína em relação aos derivados de purinas urinários, próximo ao deste trabalho.

Os compostos nitrogenados microbianos oscilaram entre 57,03 e 70,60 g/dia. Mesmo não apresentando diferença ( $\mathrm{P}>0,05)$, a produção de compostos nitrogenados microbianos apresentou os menores valores para o nível de 1,95\% de uréia. Maeng \& Baldwin (1976), citados pelo NRC (2001), relataram maior produção microbiana quando foram adicionados aminoácidos (25\%) à uréia, em relação a 100\% de uréia, como fonte de compostos nitrogenados para microrganismos.

\section{Conclusões}

A produção e as eficiências microbianas mostraram-se superiores para os animais holandeses, intermediárias para os mestiços e inferiores para os zebuínos.

A estimativa da produção de compostos nitrogenados microbianos pode ser feita a partir da excreção dos derivados de purinas na urina.

Sugere-se que a excreção urinária dos derivados de purinas seja determinada utilizando a equação de Orellana Boero et al. (2001).

A coleta spot de urina consiste em metodologia rápida e eficaz na estimativa da excreção urinária dos derivados de purinas e da produção de compostos nitrogenados microbianos.

\section{Literatura Citada}

AGRICULTURAL AND FOOD RESEARCH COUNCIL - AFRC. Energy and protein requirements of ruminants. Wallingford CAB international, 1993. 159p.

AGRICULTURAL RESEARCH COUNCIL - ARC. The nutrient requirements of ruminant livestock. London: 1980. 45p

BARBOSA, A.M.; VALADARES, R.F.D.; VALADARES FILHO, S.C. et al. Efeito do período de coleta de urina, dos níveis de concentrado e de fontes protéicas sobre a excreção de creatinina, de uréia e de derivados de purina e a produção microbiana em bovinos Nelore. Revista Brasileira de Zootecnia, v.35, n.3, p.870-877, 2006. 
BLUMMEL, M.; LEBZIEN, P. Predicting ruminal microbial efficiencies of dairy rations by in vitro techniques. Livestock Production Science, v.68, p.107-117, 2001.

CABRAL, L.S. Avaliação de alimentos para ruminantes por intermédio de métodos in vivo e in vitro. Viçosa, MG: Universidade Federal de Viçosa, 2002. 133p. Tese (Doutorado em Zootecnia) - Universidade Federal de Viçosa, 2002.

CARDOSO, R.C.; VALADARES FILHO, S.C.; COELHO DA SILVA, J.F. et al. Síntese microbiana, pH e concentração de amônia ruminal e balanço de compostos nitrogenados, em novilhos F1 Limousin x Nelore. Revista Brasileira de Zootecnia, v.29, p.1844-1852, 2000.

CECAVA, M.J.; MERCHEN, N.R.; GAY, L.C. et al. Composition of ruminal bacteria harvest from steers as influenced by dietary energy level, feeding frequency, and isolation techniques. Journal of Dairy Science, v.73, p.2480-2488, 1990.

CHEN, X.B.; GOMES, M.J. Estimation of microbial protein supply to sheep and cattle based on urinary excretion of purine derivatives - an overview of technical details. Bucksburnd: Rowett Research Institute/International Feed Research Unit, 1992. 21p. (Occasional publication).

CHEN, X.B.; MEJIA, A.T.; KYLE, D.J. et al. Evaluation of the use of the purine derivative: creatinine ratio in spot urine and plasma samples as an index of microbial protein supply in ruminants: studies in sheep. Journal of Agricultural Science, v.125, p.137-143, 1995.

CHIZZOTTI, M.L.; VALADARES FILHO, S.C.; VALADARES, R.F.D. et al. Consumo, digestibilidade e excreção de uréia e derivados de purinas em vacas de diferentes níveis de produção de leite Revista Brasileira de Zootecnia, v.36, p.138-146, 2007.

CLARK, J.H.; KLUSMEYER, T.H.; CAMERON, M.R. Microbial protein synthesis and flows of nitrogen fractions to the duodenum of dairy cows. Journal of Dairy Science, v.75, p.2304-2323, 1992.

De BOEVER, J.L.; IANTCHEVA, N.; COTTYN, B.G. et al. Microbial protein synthesis in growing-finishing bulls estimated from the urinary excretion of purine derivatives. Animal Feed Science and Technology, v.75, p.93-109, 1998.

DIAS, H.L.C.; VALADARES FILHO, S.C.; COELHO DA SILVA, J.F. et al. Eficiência de síntese microbiana, pH e concentrações ruminais de amônia, em novilhos F1 Limousin x Nelore. Revista Brasileira de Zootecnia, v.29, p.555-563, 2000

FIRKINS, J.L.; ALLEN, M.S.; OLDICK, B.S. et al. Modeling ruminal digestibility of carbohydrates and microbial protein flow to the duodenum. Journal of Dairy Science, v.81, p.3350-3369, 1998.

FUJIHARA, T.; ØRSKOV, E.R.; REEDS, P.J. et al. The effect of protein infusion on urinary excretion of purine derivatives in ruminants nourished by intragastric nutrition. Journal of Agricultural Science, v.109, p.7-12, 1987.

HALL, B.H. Recent advanced in non-NDF carbohydrates for the nutrition of lactating cows. In: SINLEITE - BOVINOCULTURA DE LEITE: NOVOS CONCEITOS EM NUTRIÇÃO, 2., 2001, Lavras. Anais... Lavras: Universidade Federal de Lavras, 2001. p.161-178.

ÍTAVO, L.C.V.; VALADARES FILHO, S.C.; SILVA, F.F. et al. Produção microbiana e parâmetros ruminais em novilhos alimentados com dietas contendo vários níveis de concentrado. Revista Brasileira de Zootecnia, v.31, p.1553-1561, 2002.

KROPP, J.R.; JOHNSON, R.R.; MALES, J.R. et al. Microbial protein synthesis with low quality roughage rations: isonitrogenous substitution of urea for soybean meal. Journal of Animal Science, v.46, p.837-843, 1977.

LEÃO, M.I. Metodologias de coletas de digestas omasal e abomasal em novilhos submetidos a três níveis de ingestão: consumo, digestibilidade e produção microbiana. Belo Horizonte: Universidade Federal de Minas Gerais, 2002. 57p. Tese (Doutorado em Ciência Animal) - Universidade Federal de Minas Gerais, 2002.
LEÃO, M.I.; VALADARES FILHO, S.C.; RENNÓ, L.N. et al. Consumos e digestibilidades totais e parciais de matéria seca, matéria orgânica,proteína bruta e extrato etéreo em novilhos submetidos a três níveis de ingestão e duas metodologias de coleta de digestas abomasal e omasal. Revista Brasileira de Zootecnia, v.33, n.6, p.1604-1615, 2004.

MARTÍN-ORÚE, S.S.; BALCELLS, J.; GUADA, J.A. et al. Microbial nitrogen production in growing heifers: direct measurement of duodenal flow of purine bases versus urinary excretion of purine derivatives as estimation procedures. Animal Feed Science and Technology, v.88, p.171-188, 2000.

NATIONAL RESEARCH COUNCIL - NRC. Nutrient requirements of beef cattle. 7.ed. Washington, DC: National Academy, 1996. 242p.

NATIONAL RESEARCH COUNCIL - NRC. Nutrient requirements of dairy cattle. 6.ed. Washinton, D.C.: National Academic Press, 1989. 158p.

NATIONAL RESEARCH COUNCIL - NRC. Nutrient requirements of dairy cattle. 7.ed. Washinton, D.C.: National Academic Press, 2001. 381p.

OLIVEIRA, A.S.; VALADARES, R.F.D; VALADARES FILHO, S.C. et al. Produção de proteína microbiana e estimativas das excreções de derivados de purinas e de uréia em vacas lactantes alimentadas com rações contendo diferentes níveis de compostos nitrogenados não protéicos. Revista Brasileira de Zootecnia, v.30, p.1621-1629, 2001.

ORELLANA BOERO, P.; BALCELLS, J.; MARTÍN-ORÚE, S.M. et al. Excretion of derivatives in cows: endogenous contribution and recovery of exogenous purine bases. Livestock Production Science, v.68, p.243-250, 2001.

OWENS, F.N.; GOETSCH, A.L. Digesta passage and microbial protein synthesis. In: MILLIGAN, L.P.; GROVUM, W.L.; DOBSON, A. (Eds.). Control of digestion and metabolism in ruminants. London: Prentice Hall, 1986. p.196-226.

PEREZ, J.F.; BALCELLS, J.; GUADA, J.A. et al. Determination of rumen microbial-nitrogen production in sheep: a comparison of urinary purine excretion with methods using ${ }^{15} \mathrm{~N}$ and purine bases as markers of microbial-nitrogen entering the duodenum. British Journal of Nutrition, v.75, p.699-709, 1996.

RENNÓ, L.N.; VALADARES, R.F.D.; LEÃO, M.I. et al. Estimativa da produção de proteína microbiana pelos derivados de purinas na urina em novilhos. Revista Brasileira de Zootecnia, v.29, p.1223-1234, 2000.

RENNÓ, L.N.; VALADARES FILHO, S.C.; VALADARES, R.F.D. Níveis de uréia na ração de novilhos de quatro grupos genéticos: consumo e digestibilidades totais. Revista Brasileira de Zootecnia, v.34, p.1775-1785, 2005

RUSSELL, J.B.; O’CONNOR, J.D.; FOX, D.G. A net carbohydrate and protein system for evaluating cattle diets: I. Ruminal fermentation. Journal of Animal Science, v.70, p.35513561, 1992.

SILVA, D.J.; QUEIROZ, A.C. Análise de alimentos (Métodos químicos e biológicos). Viçosa, MG: Universidade Federal de Viçosa, 2002. 235p.

SILVA, R.M.N.; VALADARES, R.F.D.; VALADARES FILHO, S.C. et al. Uréia para vacas em lactação. 2. Estimativas do volume urinário, da produção microbiana e da excreção de uréia. Revista Brasileira de Zootecnia, v.30, p.1948-1957, 2001.

SUSMEL, P.; STEFANON, B.; PLAZZOTTA, E. et. al. The effect of energy and protein intake on the excretion of purine derivatives. Journal of Agricultural Science, v.123, p.257266, 1994.

TIBO, G.C.; VALADARES FILHO, S.C.; COELHO DA SILVA, J.F. et al. Níveis de concentrado em dietas de novilhos mestiços F1 Simental x Nelore. 2. Balanço nitrogenado, eficiência microbiana e parâmetros ruminais. Revista Brasileira de Zootecnia, v.29, p.921-929, 2000. 
UNIVERSIDADE FEDERAL DE VIÇOSA - UFV. Sistema de análises estatísticas e genéticas - SAEG. Viçosa, MG: 1995. 85p. (Apostila).

USHIDA, K.; LASSALAS, B.; JOUANY, J.P. Determination of assay parameters for RNA analysis in bacterial and duodenal samples by spectrophotometry. Influence of sample treatment and preservation. Reproduction and Nutrition Development, v.25, p.1037- 1046, 1985.

VAGNONI, D.B.; BRODERICK, G.A.; CLAYTON, M.K. et al. Excretion of purine derivatives by Holstein cows abomasally infused with incremental amounts of purines. Journal of Dairy Science, v.80, p.1695-1702, 1997.

VALADARES FILHO, S.C. Eficiência de síntese de proteína microbiana, degradação ruminal e digestibilidade intestinal da proteína bruta, em bovinos. In: SIMPÓSIO INTERNACIONAL SOBRE EXIGÊNCIAS NUTRICIONAIS DE RUMINANTES, 1995, Viçosa, MG. Anais... Viçosa, MG: Universidade Federal de Viçosa, 1995. p.355-388.

VALADARES FILHO, S.C.; COELHO DA SILVA, J.F.; LEÃO, M.I. et al. Eficiência de síntese microbiana em novilhos holandeses, nelores e búfalos mestiços, obtida por diferentes métodos. Revista Brasileira de Zootecnia, v.19, p.424430, 1990a.

VALADARES FILHO, S.C.; COELHO DA SILVA, J.F.; SANT'ANNA, R. et al. Composição de bactérias ruminais e absorção de aminoácidos microbianos no intestino delgado de novilhos holandeses, Nelore e búfalos mestiços. Revista Brasileira de Zootecnia, v.19, p.431-440, 1990 b.

VALADARES, R.F.D.; BRODERICK, G. A.; VALADARES FILHO, S. C. et al. Effect of replacing alfafa silage with high moisture corn on ruminal protein synthesis estimated from excretion of total purine derivates. Journal of Dairy Science, v.82.p.26862696, 1999.

VALADARES, R.F.D.; GONÇALVES, L.C.; SAMPAIO, I.B. et al. Níveis de proteína em dietas de bovinos. 2. Consumo, digestibilidades e balanços de compostos nitrogenados. Revista Brasileira de Zootecnia, v.26, p.1259-1263, 1997a.

VALADARES, R.F.D.; VALADARES FILHO, S.C.; GONÇALVES, L.C. et al. Níveis de proteína em dietas de bovinos. 4 Concentrações de amônia ruminal e uréia plasmática e excreções de uréia e creatinina. Revista Brasileira de Zootecnia, v.26, p.1270-1278, 1997b.

Van SOEST, P.J. Nutritional ecology of the ruminant. Ithaca: Comstock Publication Association, 1994. 476p.

VERBIC, J.; CHEN, X.B.; MACLEOD, N.A. et al. Excretion of purine derivatives by ruminants. Effect of microbial nucleic acid infusion on purine derivative excretion by steers. Journal of Agricultural Science, v.114, p.243-248, 1990.

YU, P.; EGAN, A.R.; BOON-EK, L. et al. Purine derivatives excretion and ruminal microbial yield in growing lambs fed raw and dry roasted legume seeds as protein supplements. Animal Feed Science and Technology, v.95, p.33-48, 2002. 